\title{
Mobilização de água e conservação da viabilidade de embriões de sementes recalcitrantes de ingá (Inga vera Willd. subsp. affinis (DC.) T. D. Pennington) ${ }^{1}$
}

\author{
YARA ANDRÉO ${ }^{2,5}$, JOÃO NAKAGAWA³ e CLAUDIO JOSÉ BARBEDO ${ }^{4}$
}

(recebido: 18 de agosto de 2005; aceito: 8 de junho de 2006)

\begin{abstract}
Water mobilization and viability conservation of embryos of recalcitrant seeds of "ingá” (Inga vera Willd. subsp. affinis (DC.) T. D. Pennington). The water content of anhydrobiotic (orthodox) seeds is usually reduced to low values and its metabolism is reduced to a level that viability can be preserved for long periods. In contrast, typical non-anhydrobiotic (recalcitrant) seeds are intolerant to desiccation, possess lower longevity, and need a minimum water level to maintain viability, but the metabolism is still too active leading to a short seed longevity. In the present research "inga" seed embryos were stored in contact with polyethylene glycol 6000 (PEG) solutions, at pre-defined water potential with the objective of improving storability and longevity. Results indicated that germination of embryos kept in PEG solution at -2.4 MPa was higher than 80\% after 90 days of storage at $10^{\circ} \mathrm{C}$, while the germination of embryos kept at distilled water (0 MPa), at the same temperature, was lower than $60 \%$.
\end{abstract}

Key words - osmotic potential, physiological quality, storage

RESUMO - (Mobilização de água e conservação da viabilidade de embriões de sementes recalcitrantes de ingá (Inga vera Willd. subsp. affinis (DC.) T. D. Pennington). Sementes anidrobióticas (ortodoxas) podem ter seu teor de água reduzido a valores suficientemente baixos para minimizar o metabolismo e, dessa forma, manter a viabilidade por períodos prolongados. Sementes não-anidrobióticas (recalcitrantes) não perdem sua viabilidade desde que o teor de água seja mantido acima de determinados valores em que a quantidade da água ainda é elevada para manter o metabolismo ativo; no entanto, a longevidade dessas sementes é relativamente baixa. No presente trabalho procurou-se manter o teor de água dos embriões de ingá por meio do armazenamento em soluções de polietileno glicol 6000 (PEG), com potencial hídrico conhecido e pré-estabelecido, visando a prolongar a longevidade. Os resultados indicaram que embriões mantidos em substrato com solução de PEG a -2,4 MPa apresentaram germinação superior a $80 \%$ aos 90 dias de armazenamento a $10{ }^{\circ} \mathrm{C}$, enquanto os armazenados em substrato umedecido com água pura (0 MPa), na mesma temperatura, apresentaram germinação inferior a 60\%.

Palavras-chave - armazenamento, potencial osmótico, qualidade fisiológica

\section{Introdução}

Sementes anidrobióticas (ortodoxas) toleram secagem até a redução do seu teor de água para valores inferiores a 23\% (base úmida) e, dessa forma, têm o metabolismo reduzido até níveis que favorecem a conservação da qualidade fisiológica durante o armazenamento (Hoekstra et al. 2001, Ferreira \& Borghetti 2004). Contudo, há espécies cujas sementes

1. Parte de dissertação de mestrado da primeira autora, Programa de Pós-Graduação em Ciências Biológicas da Universidade Estadual Paulista-Botucatu.

2. Universidade Estadual Paulista, Instituto de Biociências, Caixa Postal 510, 18618-000 Botucatu, SP, Brasil.

3. Universidade Estadual Paulista, Faculdade Ciências Agronômicas, Caixa Postal 237, 18603-970 Botucatu, SP, Brasil.

4. Instituto de Botânica, Seção de Sementes e Melhoramento Vegetal, Caixa Postal 4005, 01061-970 São Paulo, SP, Brasil.

5. Autor para correspondência: yandreo@ig.com.br são intolerantes à dessecação (não-anidrobióticas), conhecidas como recalcitrantes (Roberts 1973), que apresentam baixa longevidade por serem sensíveis a reduções do teor de água abaixo de $23 \%$.

Pesquisas referentes à conservação de sementes não-anidrobióticas ainda não produziram informação suficiente para o desenvolvimento de métodos que permitam ampliar sua capacidade de armazenamento. A tolerância à dessecação vem sendo estudada, mas, até o presente momento, as pesquisas não apontam para o sucesso na utilização da secagem como forma de armazenar essas sementes por períodos prolongados e métodos alternativos devem também ser testados (Barbedo \& Marcos Filho 1998).

Sementes não-anidrobióticas geralmente apresentam atividade metabólica intensa, tanto durante sua formação, quanto após sua colheita, por serem mantidas com teores de água relativamente elevados (Barbedo \& Marcos Filho 1998, Castro et al. 2004a). Nessa situação, pode ocorrer a protrusão da raiz primária durante o armazenamento, em condições que não 
favorecem a continuidade do processo, devido à insuficiência de água para a manutenção do crescimento do eixo embrionário. Ao mesmo tempo, a intensa atividade respiratória e de consumo podem determinar redução acentuada da disponibilidade de reservas e metabolismo desordenado, com liberação e atividade de radicais livres que provocam prejuízos à conservação da viabilidade durante o armazenamento, pois favorecem a rápida deterioração (Barbedo \& Marcos Filho 1998, Ferreira \& Borghetti 2004).

Métodos alternativos para o armazenamento das sementes recalcitrantes devem obrigatoriamente considerar a redução desse metabolismo intenso e desordenado. O emprego de reguladores de crescimento vegetal, tais como o ácido abscísico (ABA) que, em diversas situações, inibe a germinação, pode resultar em algum sucesso, como verificado para sementes de Eugenia brasiliensis Lam. (Goldbach 1979) e de Inga uruguensis Hook. \& Arn. (Barbedo \& Cicero 2000). Uma opção que começa a se apresentar como promissora para o controle do metabolismo é a regulação da mobilização da água na semente.

A hidratação controlada vem sendo utilizada em sementes de leguminosas (Powell 1998) e pode ser efetuada mediante exposição dessas sementes a determinadas condições da atmosfera, embebição em substrato úmido ou imersão em soluções osmóticas, podendo ser realizada continuamente até níveis programados de hidratação (Carvalho et al. 2000). A imersão em soluções osmóticas com potencial hídrico conhecido permite, ainda, estimar o potencial hídrico de sementes e embriões (Pammenter et al. 2002, Sun 2002). Uma das soluções mais utilizadas para este tipo de tratamento é o polietileno glicol (PEG), que é um polímero de alto peso molecular, não iônico, inerte (Steuter et al. 1981) e que não apresenta sinais de toxicidade para as sementes.

Inga vera Wild. subsp. affinis (DC.) T.D. Pennington era conhecida anteriormente como Inga uruguensis Hook. \& Arn. e, popularmente, chamada de ingazeiro, ingá-banana ou ingá, pertence à família Fabaceae, sub-família Mimosoideae (Joly 1993) e possui sementes não-anidrobióticas (Bilia et al. 2003). Dados relativos ao comportamento das sementes de ingá durante o armazenamento indicam que estejam situadas entre as de maior intolerância à dessecação e de mais baixa longevidade natural (Bilia \& Barbedo 1997). Essas sementes mostram-se, então, como de grande interesse nos estudos que visam ao desenvolvimento de procedimentos para ampliar a capacidade de armazenamento de sementes recalcitrantes (Bilia et al. 2003).

O presente trabalho visou determinar, numa primeira etapa, curvas de hidratação para embriões excisados de Inga uruguensis, mantidos em substratos umedecidos com soluções de polietileno glicol 6000, identificando o ponto de equilíbrio higroscópico entre o embrião e o meio, a $10 \pm 1{ }^{\circ} \mathrm{C}$. Na segunda etapa, a partir da definição do estado de equilíbrio higroscópico num nível previamente estabelecido, buscou-se avaliar as alterações do potencial fisiológico dos embriões mantidos sob controle hídrico, com vistas à ampliação de seu potencial de armazenamento.

\section{Material e métodos}

Coleta dos frutos e beneficiamento das sementes - Frutos de ingá (Inga vera Willd. subsp. affinis (DC.) T.D. Pennington) foram coletados nos meses de fevereiro de 2002 e janeiro de 2003, a partir de aproximadamente 20 matrizes plantadas na área pertencente ao Centro de Exposições Imigrantes, São Paulo, SP (233' S e $46^{\circ} 37^{\prime} \mathrm{W}, 778 \mathrm{~m}$ de altitude).

Os frutos da primeira coleta foram levados ao Laboratório de Análise de Sementes do Instituto de Botânica (São Paulo, SP) e, os da segunda, ao Laboratório de Análise de Sementes da Faculdade de Ciências Agronômicas, UNESP (Botucatu, SP). Nas duas coletas foi realizado o beneficiamento manual, com a retirada das sementes das vagens e da sarcotesta (tegumento) que as reveste (Oliveira \& Beltrati 1992), obtendo-se os embriões excisados utilizados nos experimentos. Como a espécie produz sementes poliembriônicas, os embriões contidos em cada semente foram mantidos juntos em todas as avaliações.

Desidratação e hidratação controladas - Para este estudo utilizaram-se embriões de frutos da primeira coleta, em dois estádios de maturação, separados pela coloração de suas cascas no momento da colheita (Figliolia \& Kageyama 1994) e classificados de acordo com Munsell (1952) em fruto verdeclaro (FVC) ou Greenish Green-yellow (7,5 GY 6/10) e fruto amarelo (FA) ou Yellowish (7,8 GY 8/10). Os embriões obtidos foram submetidos a três graus de secagem, ou seja, a) Sem Secagem (SS), embriões recém-coletados, sem alterações no teor de água inicial; b) Secagem Leve (SL), embriões mantidos em laboratório $\left(24 \pm 2{ }^{\circ} \mathrm{C}\right)$ por 48 horas, até atingirem aproximadamente $51 \%$ de água; c) Secagem Crítica (SC), embriões mantidos em laboratório durante 120 horas $\left(25 \pm 2{ }^{\circ} \mathrm{C}\right.$ ), para desidratação até cerca de $35 \%$ de água. Após a secagem, os embriões SS, SL e SC foram mantidos em contato com substrato umedecido com água destilada (0 MPa) ou com soluções de polietileno glicol 6000 (PEG 6000 ) a $-0,8,-1,6,-2,4$ e $-3,2 \mathrm{MPa}$ a $10 \pm 1{ }^{\circ} \mathrm{C}$ (Michel \& Kaufmamm 1973).

Para a instalação do experimento utilizaram-se caixas de plástico transparente (gerbox), com duas folhas de papel mata- 
borrão, que foram previamente umedecidas com água ou com as soluções de PEG 6000, na proporção de duas vezes e meia a massa que apresentavam quando secas. As caixas foram colocadas no interior de câmaras escuras com circulação de água, a $10 \pm 1^{\circ} \mathrm{C}$, mantendo-se elevada umidade relativa do ar (100\%) para impedir a desidratação do substrato. Foram utilizadas quatro repetições e, a cada 72 horas, foram retiradas amostras aleatórias de dez embriões por repetição, de cada tratamento, para avaliação do teor de água, pelo método de estufa a $105 \pm 3^{\circ} \mathrm{C}$ por 24 horas (Brasil 1992). Os resultados foram expressos em porcentagem, com base na massa fresca dos embriões.

Armazenamento dos embriões - Baseando-se nos resultados obtidos das curvas de hidratação, foram selecionados os potenciais osmóticos de -1,6 MPa e de -2,4 MPa, além do controle (0 MPa, água destilada), para o armazenamento dos embriões excisados de frutos da segunda coleta, separados em três diferentes estádios de maturação, obedecendo ao critério de coloração da casca (Figliolia \& Kageyama 1994) e classificados de acordo com Munsell (1952) em frutos verdes (FV) ou Greenish Green-yellow (7,5 GY 4/6), frutos verdeclaros (FVC) ou Greenish Green-yellow (7,5 GY 6/10) e frutos amarelos (FA) ou Yellowish (7,8 GY 8/10).

Embriões de cada estádio de maturação foram colocados em gerbox, nos substratos com diferentes potenciais osmóticos, embalados em sacos de polietileno (espessura $0,05 \mathrm{~mm}$ ), e vedados com fita adesiva para impedir a desidratação do substrato. $\mathrm{O}$ armazenamento dos embriões foi realizado em câmaras incubadoras B.O.D., com temperatura de $10 \pm 1^{\circ} \mathrm{C}$ (Bilia et al. 1999, Barbedo \& Cicero 2000) e sem a presença de luz.

Logo após a colheita e com intervalos de 30 dias, até 90 dias, os embriões foram avaliados quanto ao teor de água e germinação. Antes da avaliação os embriões foram lavados em água corrente, para a retirada superficial da solução de PEG (Pertel et al. 2001).

O teor de água foi determinado pelo mesmo método utilizado para a curva de hidratação. O teste de germinação foi conduzido com quatro repetições de 25 embriões distribuídos em rolo de papel germitest, em câmara de germinação sem luz, a $30^{\circ} \mathrm{C}$. As avaliações foram realizadas aos sete (primeira contagem) e 14 dias (contagem final) após a semeadura, sendo consideradas plântulas normais as que possuíam parte aérea e sistema radicular proporcional e desenvolvido, utilizando-se o mesmo critério para sementes poliembriônicas, para pelo menos uma das plântulas (Bilia \& Barbedo 1997).

Delineamento experimental e análise estatística dos dados No primeiro experimento, para a obtenção das curvas de hidratação, foi utilizado o delineamento inteiramente casualizado, em esquema fatorial $2 \times 5 \times 5$ (estádio de maturação $\times$ potencial osmótico $\times$ período de armazenamento), para cada nível de secagem. No segundo experimento, para o armazenamento dos embriões, foi utilizado fatorial $3 \times 3 \times 4$ (estádio de maturação $\times$ potencial osmótico $\times$ período de armazenamento). Os dados obtidos foram submetidos à análise da variância, testando-se a significância de regressões polinomiais (Vieira \& Hoffman 1989), sendo a significância pré-estabelecida em 5\%. Quando necessária a correção da normalidade e da heterogeneidade, os dados em porcentagem, de teor de água e de germinação foram transformados em arc $\operatorname{sen}(\mathrm{x} / 100)^{0,5}$.

\section{Resultados e Discussão}

Desidratação e hidratação controladas - A análise da variância foi significativa para os efeitos principais e para as interações. O teor de água dos embriões de frutos com coloração amarela (FA), 63\% (figura 1A), foi próximo ao de frutos maduros obtidos por Bilia \& Barbedo (1997), Bilia et al. (1999), Barbedo \& Cicero (1998) e Faria et al. (2004), indicando sua proximidade à dispersão natural. Esses embriões tiveram potencial hídrico suficientemente negativo para embeber em água pura (0 MPa), aumentando o teor de água até valores próximos a 70\% durante as 288 horas de embebição, aproximando-se ao teor de água dos embriões de frutos de coloração verde-claro (FVC) que não se alteraram durante esse período (figura 1A). Portanto, quando o armazenamento é realizado em substrato com água disponível, evitando-se o estresse hídrico descrito por Pammenter et al. (1994), embriões maduros de ingá continuam embebendo e, provavelmente, em processo de germinação, visto que essa ocorre, ainda que lentamente, mesmo em temperatura de $10{ }^{\circ} \mathrm{C}$ (Faria et al. 2004).

Não houve re-embebição por água em embriões de FA mantidos em substrato com potencial hídrico igual ou inferior a -0,8 $\mathrm{MPa}$, os quais mantiveram teor de água próximo a $62 \%$ (figuras 1B-E). Tal fato pode significar que o potencial hídrico desses embriões estava próximo a -1,0 MPa, o que corroboraria os resultados de Faria et al. (2004).

Embriões imaturos não embeberam em água (figura 1A) e perderam água para o meio quando em potencial hídrico inferior a -1,6 MPa (figuras 1D-E), o que seria esperado uma vez que o potencial hídrico desses embriões pode estar próximo a 0,0 MPa (Faria et al. 2004).

A desidratação e reidratação controladas mostraram que, após a secagem leve, os embriões tiveram o teor de água reduzido para valores próximos a 57\%-62\% (figura 2), ocorrendo embebição em água pura e no potencial de -0,8 MPa (figuras 2A-B), mas não nos potenciais mais negativos (figuras $2 \mathrm{C}-\mathrm{E}$ ) e, especificamente para embriões de FVC, houve perda 

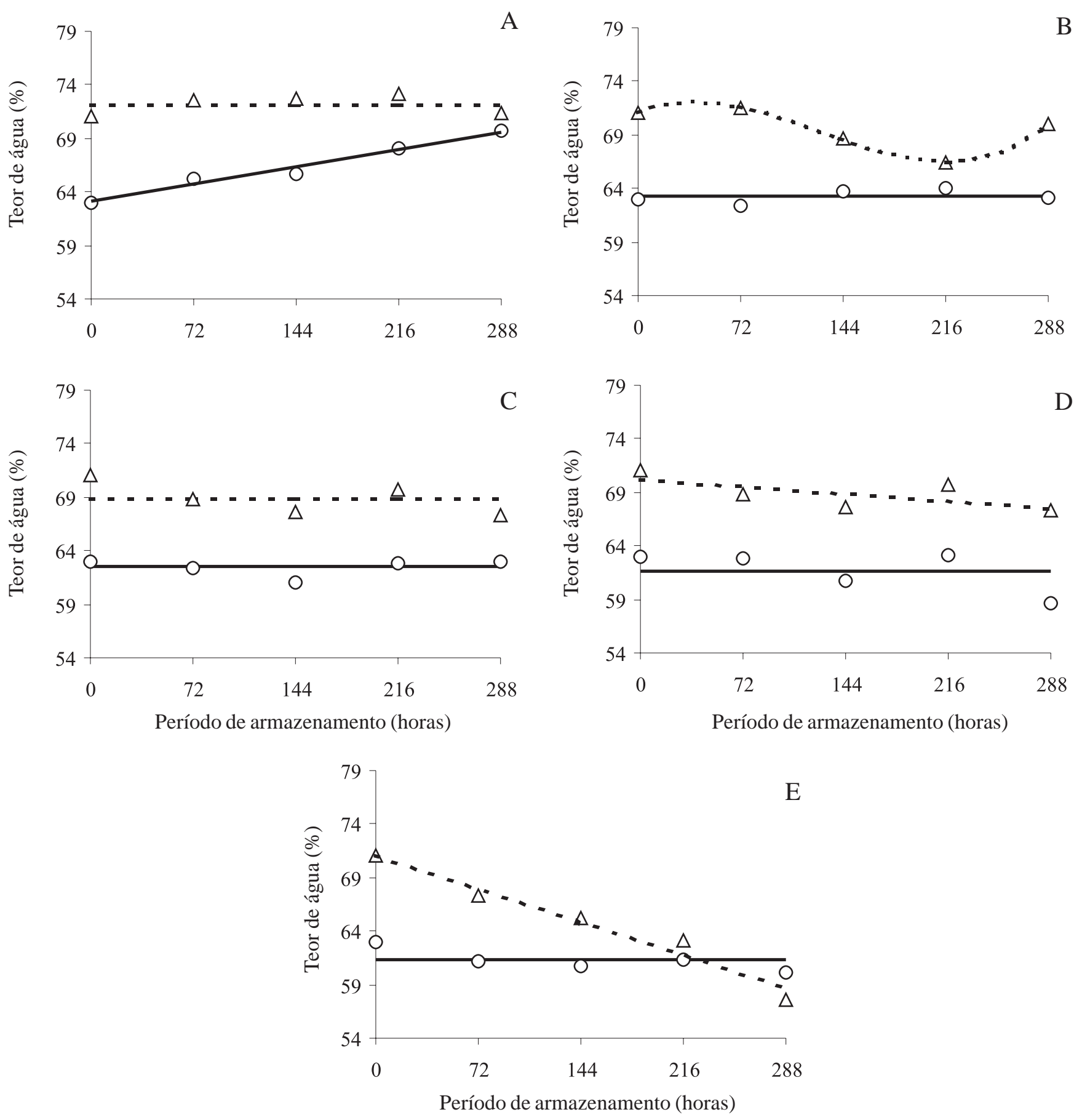

Figura 1. Perfis de hidratação para embriões de ingá, sem secagem, colhidos nos estádios de maturação fruto verde-claro (FVC, $\Delta$, ---) e fruto amarelo (FA, O, - ), submetidos aos potenciais osmóticos de 0,0 MPa (A), -0,8 MPa (B), -1,6 MPa (C), -2,4 MPa (D) e-3,2 MPa (E). Regressões $(P<0,05)$ : $\mathrm{Y}_{\mathrm{FVC}, \mathrm{A}}=71,13 ; \mathrm{Y}_{\mathrm{FA}, \mathrm{A}}=63,26+0,0203 \mathrm{X}\left(\mathrm{R}^{2}=0,96\right) ; \mathrm{Y}_{\mathrm{FVC}, \mathrm{B}}=70,998+0,0546 \mathrm{X}-0,0008 \mathrm{X}^{2}$ $-0,06 X^{3}\left(R^{2}=0,99\right) ; Y_{F A, B}=63,14 ; Y_{\mathrm{FVC}, \mathrm{C}}=68,93 ; \mathrm{Y}_{\mathrm{FA}, \mathrm{C}}=62,47 ; \mathrm{Y}_{\mathrm{FVC}, \mathrm{D}}=70,152-0,0155 \mathrm{X}\left(\mathrm{R}^{2}=0,85\right) ; \mathrm{Y}_{\mathrm{FA}, \mathrm{D}}=61,68 ; \mathrm{Y}_{\mathrm{FVC}, \mathrm{E}}=71,074$ - 0,0431X $\left(R^{2}=0,96\right) ; Y_{\mathrm{FA}, \mathrm{E}}=61,33$.

Figure 1. Imbibition course of ingá embryos with no drying from light-green (FVC, $\Delta,---)$ and yellow (FA, $\mathrm{O}$, 一) fruits at $0.0 \mathrm{MPa}$ (A), -0.8 MPa (B), -1.6 MPa (C), -2.4 MPa (D) and -3.2 MPa (E). Regressions $(P<0.05)$ : $\mathrm{Y}_{\mathrm{FVC}, \mathrm{A}}=71.13 ; \mathrm{Y}_{\mathrm{FA}, \mathrm{A}}=63.26+0.0203 \mathrm{X}$ $\left(\mathrm{R}^{2}=0.96\right) ; \mathrm{Y}_{\mathrm{FVC}, \mathrm{B}}=70.998+0.0546 \mathrm{X}-0.0008 \mathrm{X}^{2}-0.06 \mathrm{X}^{3}\left(\mathrm{R}^{2}=0.99\right) ; \mathrm{Y}_{\mathrm{FA}, \mathrm{B}}=63.14 ; \mathrm{Y}_{\mathrm{FVC}, \mathrm{C}}=68.93 ; \mathrm{Y}_{\mathrm{FA}, \mathrm{C}}=62.47 ; \mathrm{Y}_{\mathrm{FVC}, \mathrm{D}}=70.152$ - 0.0155X $\left(\mathrm{R}^{2}=0.85\right) ; \mathrm{Y}_{\mathrm{FA}, \mathrm{D}}=61.68 ; \mathrm{Y}_{\mathrm{FVC}, \mathrm{E}}=71.074-0.0431 \mathrm{X}\left(\mathrm{R}^{2}=0.96\right) ; \mathrm{Y}_{\mathrm{FA}, \mathrm{E}}=61.33$. 

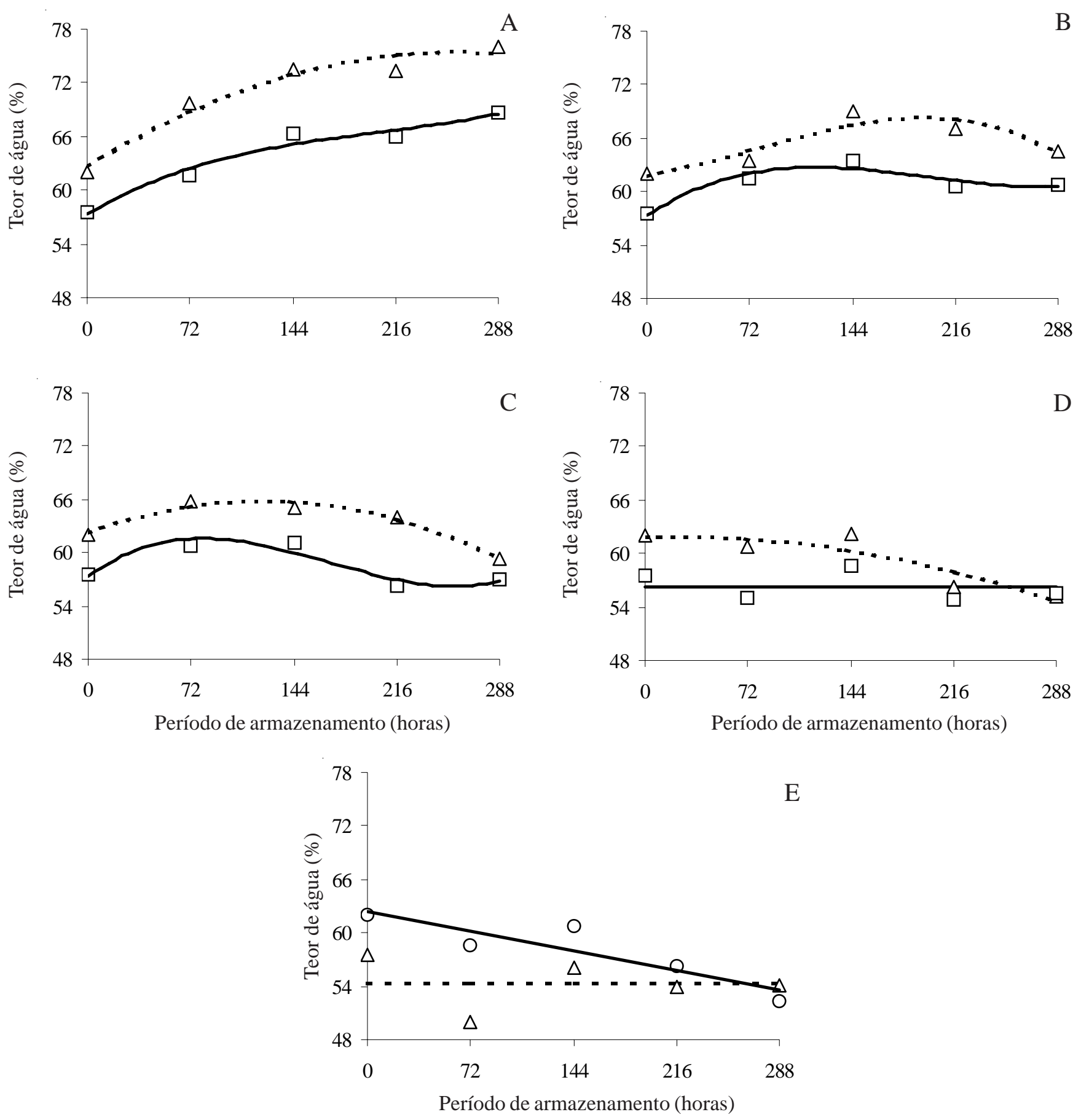

Figura 2. Perfis de hidratação para embriões de ingá, submetidos à secagem leve, colhidos nos estádios de maturação fruto verde-claro (FVC, $\Delta$, ---) e fruto amarelo (FA, O, - ) e mantidos nos potenciais osmóticos de 0,0 MPa (A), -0,8 MPa (B), -1,6 MPa (C), -2,4 MPa (D) e -3,2 MPa (E). Regressões $(P<0,05): Y_{\mathrm{FVC}, \mathrm{A}}=61,471+0,000607 \mathrm{X}-0,0001 \mathrm{X}^{2}\left(\mathrm{R}^{2}=0,77\right) ; \mathrm{Y}_{\mathrm{FA}, \mathrm{A}}=57,234+0,1097 \mathrm{X}$ $-0,0007 X^{2}+0,6 X^{3}\left(R^{2}=0,90\right) ; Y_{F V C, B}=61,73+0,0266 X+0,0002 X^{2}-0,6 X^{3}\left(R^{2}=0,82\right) ; Y_{F A, B}=57,3+0,1061 X-0,0006 X^{2}-0,6 X^{3}$ $\left(R^{2}=0,90\right) ; Y_{F V C, C}=62,469+0,0338 X-0,0002 X^{2}\left(R^{2}=0,62\right) ; Y_{F A, C}=57,221+0,1198 X-0,001 X^{2}-0,06 X^{3}\left(R^{2}=0,89\right) ; Y_{F V C, D}=56,78$; $\mathrm{Y}_{\mathrm{FA}, \mathrm{D}}=61,886+0,0029 \mathrm{X}-0,0001 \mathrm{X}^{2}\left(\mathrm{R}^{2}=0,81\right) ; \mathrm{Y}_{\mathrm{FVC}, \mathrm{E}}=62,362-0,0303 \mathrm{X}\left(\mathrm{R}^{2}=0,80\right) ; \mathrm{Y}_{\mathrm{FA}, \mathrm{E}}=54,31$.

Figure 2. Imbibition course of ingá embryos after soft drying, from light-green (FVC, $\Delta,---)$ and yellow (FA, O, - ) fruits at 0.0 $\mathrm{MPa}(\mathrm{A}),-0.8 \mathrm{MPa}(\mathrm{B}),-1.6 \mathrm{MPa}(\mathrm{C}),-2.4 \mathrm{MPa}(\mathrm{D})$ and -3.2 MPa (E). Regressions $(P<0.05): \mathrm{Y}_{\mathrm{FVC}, \mathrm{A}}=61.471+0.000607 \mathrm{X}-0.0001 \mathrm{X}^{2}$ $\left(\mathrm{R}^{2}=0.77\right) ; \mathrm{Y}_{\mathrm{FA}, \mathrm{A}}=57.234+0.1097 \mathrm{X}-0.0007 \mathrm{X}^{2}+0.6 \mathrm{X}^{3}\left(\mathrm{R}^{2}=0.90\right) ; \mathrm{Y}_{\mathrm{FVC}, \mathrm{B}}=61.73+0.0266 \mathrm{X}+0.0002 \mathrm{X}^{2}-0.6 \mathrm{X}^{3}\left(\mathrm{R}^{2}=0.82\right) ; \mathrm{Y}_{\mathrm{FA}, \mathrm{B}}=57.3$ $+0.1061 X-0.0006 X^{2}-0.6 X^{3}\left(R^{2}=0.90\right) ; Y_{F V C, C}=62.469+0.0338 X-0.0002 X^{2}\left(R^{2}=0.62\right) ; Y_{F A, C}=57.221+0.1198 X-0.001 X^{2}-0.06 X^{3}$ $\left(\mathrm{R}^{2}=0.89\right) ; \mathrm{Y}_{\mathrm{FVC}, \mathrm{D}}=56.78 ; \mathrm{Y}_{\mathrm{FA}, \mathrm{D}}=61.886+0.0029 \mathrm{X}-0.0001 \mathrm{X}^{2}\left(\mathrm{R}^{2}=0.81\right) ; \mathrm{Y}_{\mathrm{FVC}, \mathrm{E}}=62.362-0.0303 \mathrm{X}\left(\mathrm{R}^{2}=0.80\right) ; \mathrm{Y}_{\mathrm{FA}, \mathrm{E}}=54.31$. 
de água para o meio (figura 2D).

Com a secagem crítica, os embriões tiveram seu teor de água reduzido para valores próximos a $26 \%$, que equivaleria a potencial hídrico de, aproximadamente, -20 MPa (Faria et al. 2004). A diferença entre esse potencial hídrico e o das soluções, inclusive a mais concentrada (-3,2 MPa), resultou em rápida absorção de água pelos embriões (figura 3), atingindo teores de água de, aproximadamente, $64 \%$ em 0,0 MPa, 54\% em $-0,8 \mathrm{MPa}, 50 \%$ a $-1,6 \mathrm{MPa}, 44 \%$ a $-2,4 \mathrm{MPa}$ e $40 \%$ a $-3,2 \mathrm{MPa}$ (figura 3A-E).

O teor de água elevado dos embriões permite a germinação e o crescimento inicial da raiz primária (Castro et al. 2004b). Com a manutenção dos embriões de ingá em substrato com água pura, houve embebição ou, ao menos, manutenção de seus elevados teores de água após 288 horas (figura 1A) e, portanto, pode-se supor que houve metabolismo e consumo de reservas no período, diminuindo a capacidade de manutenção da viabilidade desses embriões. $\mathrm{O}$ armazenamento em meio com pouca restrição à disponibilidade de água, prática comum para sementes recalcitrantes e já empregada para ingá (Bilia \& Barbedo 1997, Barbedo \& Cicero $2000)$, pode, portanto, reduzir o potencial de armazenamento dessas sementes, ainda que o armazenamento seja realizado em baixas temperaturas.

Por outro lado, embriões mantidos em potencial hídrico mais negativo, principalmente os mantidos em 1,6 MPa e -2,4 MPa, permaneceram com teor de água próximo a 63\%-69\% após 288 horas (figuras 1C-D) e, talvez, foram impedidos de iniciar o crescimento da raiz primária, visto que, segundo Castro et al. (2004b), em potencial hídrico igual ou inferior a -1,0 MPa a fase II da germinação torna-se relativamente mais extensa e a fase III (crescimento da raiz primária) pode não ocorrer. Nessa condição, a capacidade de manutenção da viabilidade dos embriões poderia ter sido prolongada e, conseqüentemente, o armazenamento.

Armazenamento dos embriões - A análise da variância foi significativa para os efeitos principais e para as interações. Embriões mantidos em substrato com água pura (0,0 $\mathrm{MPa})$ embeberam até 30 dias de armazenamento, quando obtidos de FV e de FVC e até 90 dias, quando de FA, atingindo teores de água de aproximadamente $70 \%$ a $80 \%$ (figura 4). Contudo, nos substratos com menores potenciais hídricos o teor de água dos embriões decresceu e permaneceu entre $65 \%$ a $67 \%$, quando em $-1,6 \mathrm{MPa}$ e entre $59 \%$ a $62 \%$, quando em -2,4 MPa.

A figura 5 apresenta os resultados de germinação dos embriões após cada período de armazenamento. Observou-se que embriões de todos os tipos de frutos e em todos os substratos tiveram sua capacidade germinativa diminuída com o armazenamento; porém, esta redução apresentou taxas diferentes entre os tratamentos. Entre os potencias osmóticos, para embriões de todos os tipos de frutos, observou-se que os melhores resultados ocorreram em potenciais negativos, -1,6 e -2,4 MPa. Embriões de FV que, armazenados a $0,0 \mathrm{MPa}$ perderam a capacidade germinativa aos 90 dias de armazenamento (figura 5A), ainda apresentavam cerca de $40 \%$ de germinação quando mantidos a -1,6 ou -2,4 MPa. Embriões de FVC e de FA com $60 \%$ e $20 \%$, respectivamente, de germinação aos 90 dias de armazenamento em água, superaram 70\%-80\% de germinação quando mantidos em soluções de -1,6 e -2,4 MPa, demonstrando que os potenciais hídricos negativos do meio foram efetivos no controle da deterioração dos embriões ou na manutenção da viabilidade dos mesmos.

Além disso, especificamente para FVC (figura 5B), pode-se observar que os embriões apresentaram menor declínio dos valores iniciais de germinação durante o armazenamento quando mantidos em -1,6 ou -2,4 MPa, demonstrando possuir maior vigor que os dos estádios FV (figura 5A) e FA (figura 5C) e, dessa forma, sugerindo que os do estádio FA pudessem ter iniciado o processo germinativo, por viviparidade, dentro do próprio fruto (Barbedo \& Marcos Filho 1998, Barbedo \& Cicero 2000).

A coleta dos frutos nos estádios de maturação de FVC e FA, principalmente naquele, mostrou-se favorável

Figure 3. Imbibition course of ingá embryos after strong drying, from light-green (FVC, $\Delta,---)$ and yellow (FA, $\mathrm{O},-$ ) fruits at 0.0 $\mathrm{MPa}(\mathrm{A}),-0.8 \mathrm{MPa}(\mathrm{B}),-1.6 \mathrm{MPa}(\mathrm{C}),-2.4 \mathrm{MPa}(\mathrm{D})$ and -3.2 MPa (E). Regressions $(P<0.05): \mathrm{Y}_{\mathrm{FVC}, \mathrm{A}}=24.175+0.5932 \mathrm{X}-0.0029 \mathrm{X}^{2}$ $-0.0006 \mathrm{X}^{3}\left(\mathrm{R}^{2}=0.99\right) ; \mathrm{Y}_{\mathrm{FA}, \mathrm{A}}=24.175+0.5932 \mathrm{X}-0.0025 \mathrm{X}^{2}-0.006 \mathrm{X}^{3}\left(\mathrm{R}^{2}=0.99\right) ; \mathrm{Y}_{\mathrm{FVC}, \mathrm{B}}=24.07+0.4704 \mathrm{X}+0.0025 \mathrm{X}^{2}-0.006 \mathrm{X}^{3}$ $\left(\mathrm{R}^{2}=0.99\right) ; \mathrm{Y}_{\mathrm{FA}, \mathrm{B}}=26.687+0.4316 \mathrm{X}-0.0024 \mathrm{X}^{2}-0.0006 \mathrm{X}^{3}\left(\mathrm{R}^{2}=0.99\right) ; \mathrm{Y}_{\mathrm{FVC}, \mathrm{C}}=25.63+0.408 \mathrm{X}-0.0025 \mathrm{X}^{2}-0.00006 \mathrm{X}^{3}\left(\mathrm{R}^{2}=0.99\right)$; $\mathrm{Y}_{\mathrm{FA}, \mathrm{C}}=26.883+0.3633 \mathrm{X}-0.0021 \mathrm{X}^{2}-0.0006 \mathrm{X}^{3}\left(\mathrm{R}^{2}=0.97\right) ; \mathrm{Y}_{\mathrm{FVC}, \mathrm{D}}=25.721+0.461 \mathrm{X}-0.0031 \mathrm{X}^{2}-0.000006 \mathrm{X}^{3}\left(\mathrm{R}^{2}=0.99\right) ; \mathrm{Y}_{\mathrm{FA}, \mathrm{D}}=26.91$ $+0.3763 X-0.0024 X^{2}-0.00006 X^{3}\left(R^{2}=0.96\right) ; Y_{F V C, E}=25.758+0.2841 X-0.0017 X^{2}-0.006 X^{3}\left(R^{2}=0.90\right) ; Y_{F A, E}=27.006+0.2755 X-$ $0.0018 X^{2}-0.0006 X^{3}\left(R^{2}=0.90\right)$. 
A
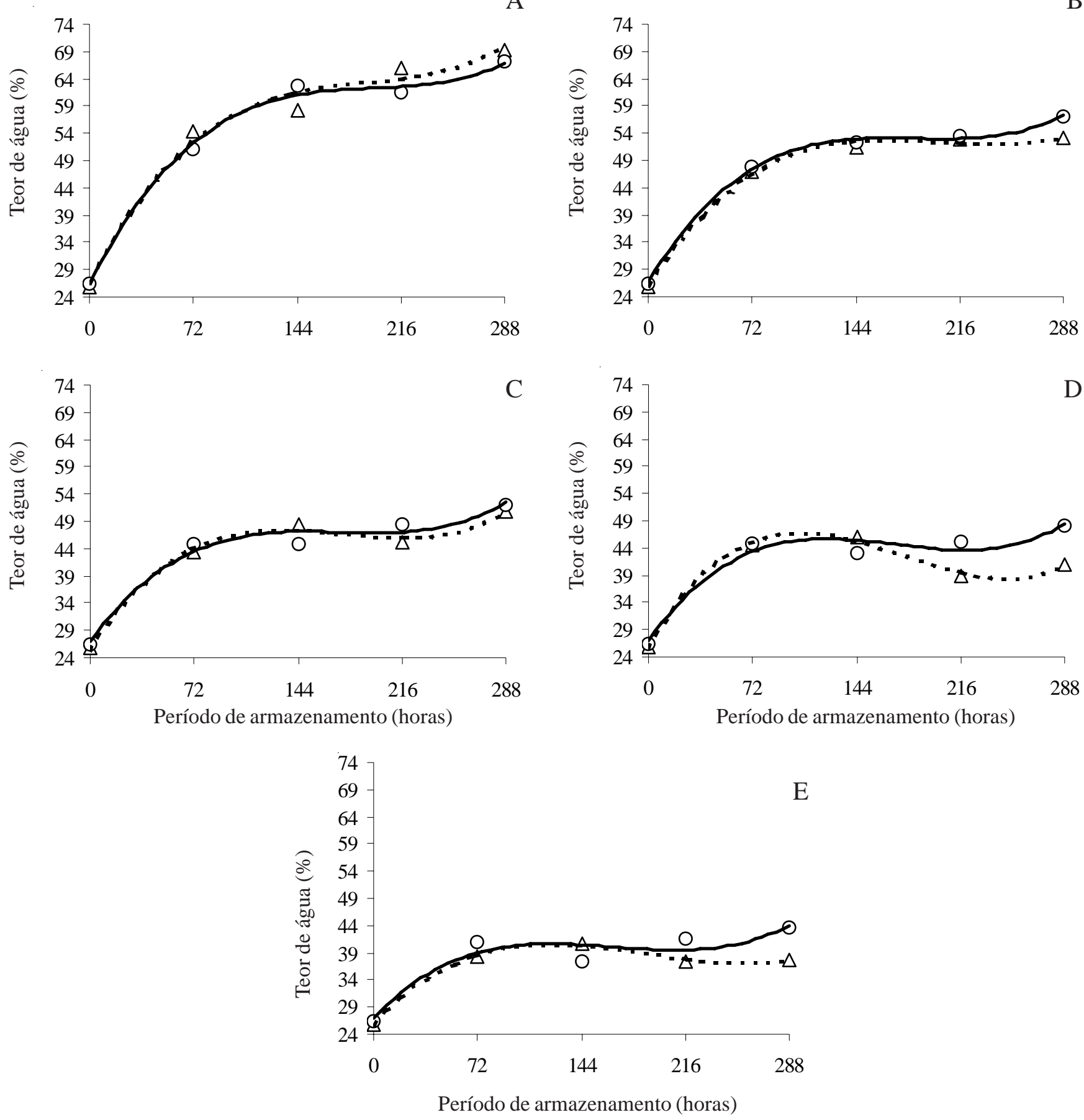

Figura 3. Perfis de hidratação para embriões de ingá, submetidos à secagem crítica, colhidos nos estádios de maturação fruto verde-claro (FVC, $\Delta$, ---) e fruto amarelo (FA, O, 一) e mantidos nos potenciais osmóticos de 0,0 MPa (A), -0,8 MPa (B), -1,6 MPa (C), -2,4 MPa (D) e -3,2 MPa (E). Regressões $(P<0,05): \mathrm{Y}_{\mathrm{FVC}, \mathrm{A}}=24,175+0,5932 \mathrm{X}-0,0029 \mathrm{X}^{2}-0,0006 \mathrm{X}^{3}\left(\mathrm{R}^{2}=0,99\right) ; \mathrm{Y}_{\mathrm{FA}, \mathrm{A}}=24,175$ $+0,5932 X-0,0025 X^{2}-0,006 X^{3}\left(R^{2}=0,99\right) ; Y_{\mathrm{FVC}, \mathrm{B}}=24,07+0,4704 \mathrm{X}+0,0025 \mathrm{X}^{2}-0,006 \mathrm{X}^{3}\left(\mathrm{R}^{2}=0,99\right) ; \mathrm{Y}_{\mathrm{FA}, \mathrm{B}}=26,687+0,4316 \mathrm{X}-$ $0,0024 \mathrm{X}^{2}-0,0006 \mathrm{X}^{3}\left(\mathrm{R}^{2}=0,99\right) ; \mathrm{Y}_{\mathrm{FVC}, \mathrm{C}}=25,63+0,408 \mathrm{X}-0,0025 \mathrm{X}^{2}-0,00006 \mathrm{X}^{3}\left(\mathrm{R}^{2}=0,99\right) ; \mathrm{Y}_{\mathrm{FA}, \mathrm{C}}=26,883+0,3633 \mathrm{X}-0,0021 \mathrm{X}^{2}-$ $0,0006 X^{3}\left(R^{2}=0,97\right) ; Y_{F V C, D}=25,721+0,461 X-0,0031 X^{2}-0,000006 X^{3}\left(R^{2}=0,99\right) ; Y_{F A, D}=26,91+0,3763 X-0,0024 X^{2}-0,00006 X^{3}$ $\left(\mathrm{R}^{2}=0,96\right) ; \mathrm{Y}_{\mathrm{FVC}, \mathrm{E}}=25,758+0,2841 \mathrm{X}-0,0017 \mathrm{X}^{2}-0,006 \mathrm{X}^{3}\left(\mathrm{R}^{2}=0,90\right) ; \mathrm{Y}_{\mathrm{FA}, \mathrm{E}}=27,006+0,2755 \mathrm{X}-0,0018 \mathrm{X}^{2}-0,0006 \mathrm{X}^{3}\left(\mathrm{R}^{2}=0,90\right)$. 

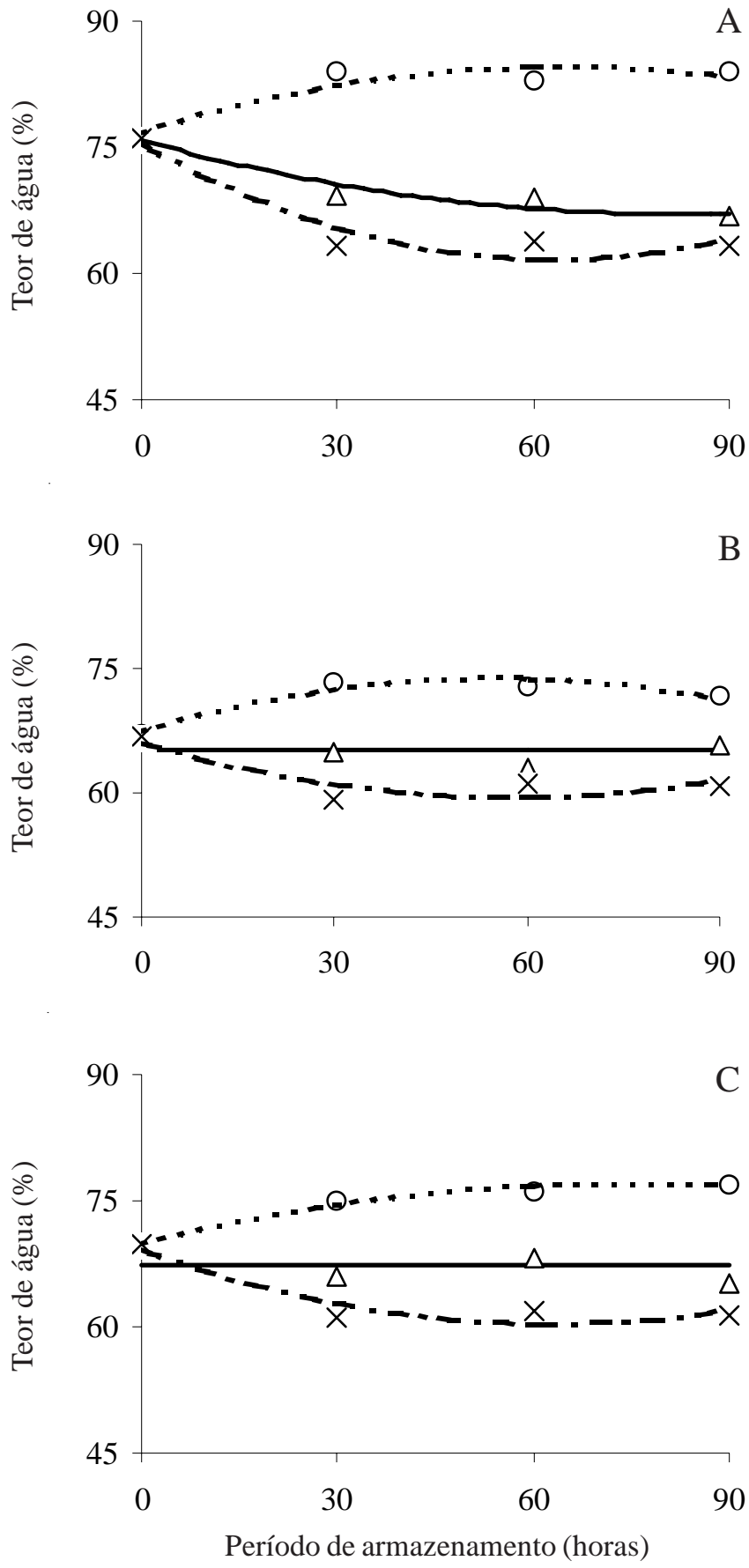

Figura 4. Teor de água de embriões de ingá colhidos nos estádios de maturação fruto verde (A), fruto verde-claro (B) e fruto amarelo (C), submetidos ao armazenamento nos potenciais osmóticos de 0,0 $\mathrm{MPa}(\mathrm{O},---),-1,6 \mathrm{MPa}(\Delta,-)$ e -2,4 MPa $(\mathrm{X},---)$. Regressões $(P<0,05)$ : $\mathrm{Y}_{0 \mathrm{MPa}, \mathrm{A}}=76,745+$ $0,2392 \mathrm{X}-0,0018 \mathrm{X}^{2}\left(\mathrm{R}^{2}=0,84\right) ; \mathrm{Y}_{-1,6 \mathrm{MPa}, \mathrm{A}}=75,783-0,2137 \mathrm{X}+$ $0,0013 \mathrm{X}^{2}\left(\mathrm{R}^{2}=0,93\right) ; \mathrm{Y}_{-2,4 \mathrm{MPa}, \mathrm{A}}=75,428-0,4369 \mathrm{X}+0,0035 \mathrm{X}^{2}$ $\left(\mathrm{R}^{2}=0,93\right) ; \mathrm{Y}_{0 \mathrm{MPa}, \mathrm{B}}=67,278+0,2342 \mathrm{X}-0,0021 \mathrm{X}^{2}\left(\mathrm{R}^{2}=0,91\right)$; $\mathrm{Y}_{-1,6 \mathrm{MPa}, \mathrm{B}}=65,112 ; \mathrm{Y}_{-2,4 \mathrm{MPa}, \mathrm{B}}=66,077-0,2312 \mathrm{X}+0,002 \mathrm{X}^{2}$ $\left(\mathrm{R}^{2}=0,78\right) ; \mathrm{Y}_{0 \mathrm{MPa}, \mathrm{C}}=69,846+70,991 \mathrm{X}+0,767 \mathrm{X}^{2}\left(\mathrm{R}^{2}=0,97\right)$; $\mathrm{Y}_{-1,6 \mathrm{MPa}, \mathrm{C}}=67,298 ; \mathrm{Y}_{-2,4 \mathrm{MPa}, \mathrm{C}}=69,106-0,2794 \mathrm{X}+0,0022 \mathrm{X}^{2}$ $\left(\mathrm{R}^{2}=0,87\right)$. ao armazenamento das sementes em substratos umedecidos com soluções de PEG 6000 que, além de estabelecerem equilíbrio higroscópico, mantiveram maior percentual de sementes vivas e com capacidade fisiológica para germinar aos 90 dias.

As soluções com potenciais osmóticos conhecidos têm sido comumente usadas visando a melhorar a velocidade e a uniformidade de germinação das sementes ortodoxas ("priming” ou osmocondicionamento, Castro et al. 2004b), mas não para fins de conservação da viabilidade das sementes recalcitrantes. Contudo, parece evidente, no presente estudo, que a manutenção de sementes ou embriões recalcitrantes em soluções com potencial osmótico negativo pode atrasar de forma expressiva o suposto processo de deterioração resultante da germinação durante o armazenamento.

De modo geral, os resultados de germinação aos 90 dias de armazenamento parecem indicar que, para sementes de ingá, o uso de substrato umedecido com soluções de PEG 6000 vem a ser um método alternativo favorável ao armazenamento e que, dessa forma, pode ser utilizado com o objetivo de ampliar o período de viabilidade das sementes não-anidrobióticas. Ficou evidente, ainda, que houve controle da taxa de germinação dos embriões durante o armazenamento, provavelmente em função do controle da mobilização da água dentro e fora dos mesmos.

Agradecimentos - Ao CNPq, pela bolsa de mestrado concedida a Y. Andréo e pela bolsa de produtividade concedida a C.J. Barbedo; à Prof. Dra Sheila Z. Pinho (Departamento de Bioestatística), pelo auxílio nas análises estatísticas e ao Centro de Exposições Imigrantes, pela concessão para coletas e obtenção do material vegetal.

Figure 4. Water content of ingá embryos from green (A), light-green (B) and yellow (C) fruits, stored at 0.0 $\mathrm{MPa}(\mathrm{O},---)$, -1.6 MPa $(\Delta,-)$ and -2.4 MPa $(\mathrm{X},---)$. Regressions $(P<0.05)$ : $\mathrm{Y}_{0 \mathrm{MPa}, \mathrm{A}}=76.745+0.2392 \mathrm{X}-0.0018 \mathrm{X}^{2}\left(\mathrm{R}^{2}=0.84\right) ; \mathrm{Y}_{-1.6 \mathrm{MPa}, \mathrm{A}}=$ $75.783-0.2137 \mathrm{X}+0.0013 \mathrm{X}^{2}\left(\mathrm{R}^{2}=0.93\right) ; \mathrm{Y}_{-2.4 \mathrm{MPa}, \mathrm{A}}=75.428-$ $0.4369 \mathrm{X}+0.0035 \mathrm{X}^{2}\left(\mathrm{R}^{2}=0.93\right) ; \mathrm{Y}_{0 \mathrm{MPa}, \mathrm{B}}=67.278+0.2342 \mathrm{X}-$ $0.0021 \mathrm{X}^{2}\left(\mathrm{R}^{2}=0.91\right) ; \mathrm{Y}_{-1.6 \mathrm{MPa}, \mathrm{B}}=65.112 ; \mathrm{Y}_{-2.4 \mathrm{MPa}, \mathrm{B}}=66.077-$ $0.2312 \mathrm{X}+0.002 \mathrm{X}^{2}\left(\mathrm{R}^{2}=0.78\right) ; \mathrm{Y}_{0 \mathrm{MPa}, \mathrm{C}}=69.846+70.991 \mathrm{X}+$ $0.767 \mathrm{X}^{2}\left(\mathrm{R}^{2}=0.97\right) ; \mathrm{Y}_{-1.6 \mathrm{MPa}, \mathrm{C}}=67.298 ; \mathrm{Y}_{-2.4 \mathrm{MPa}, \mathrm{C}}=69.106-$ $0.2794 \mathrm{X}+0.0022 \mathrm{X}^{2}\left(\mathrm{R}^{2}=0.87\right)$. 

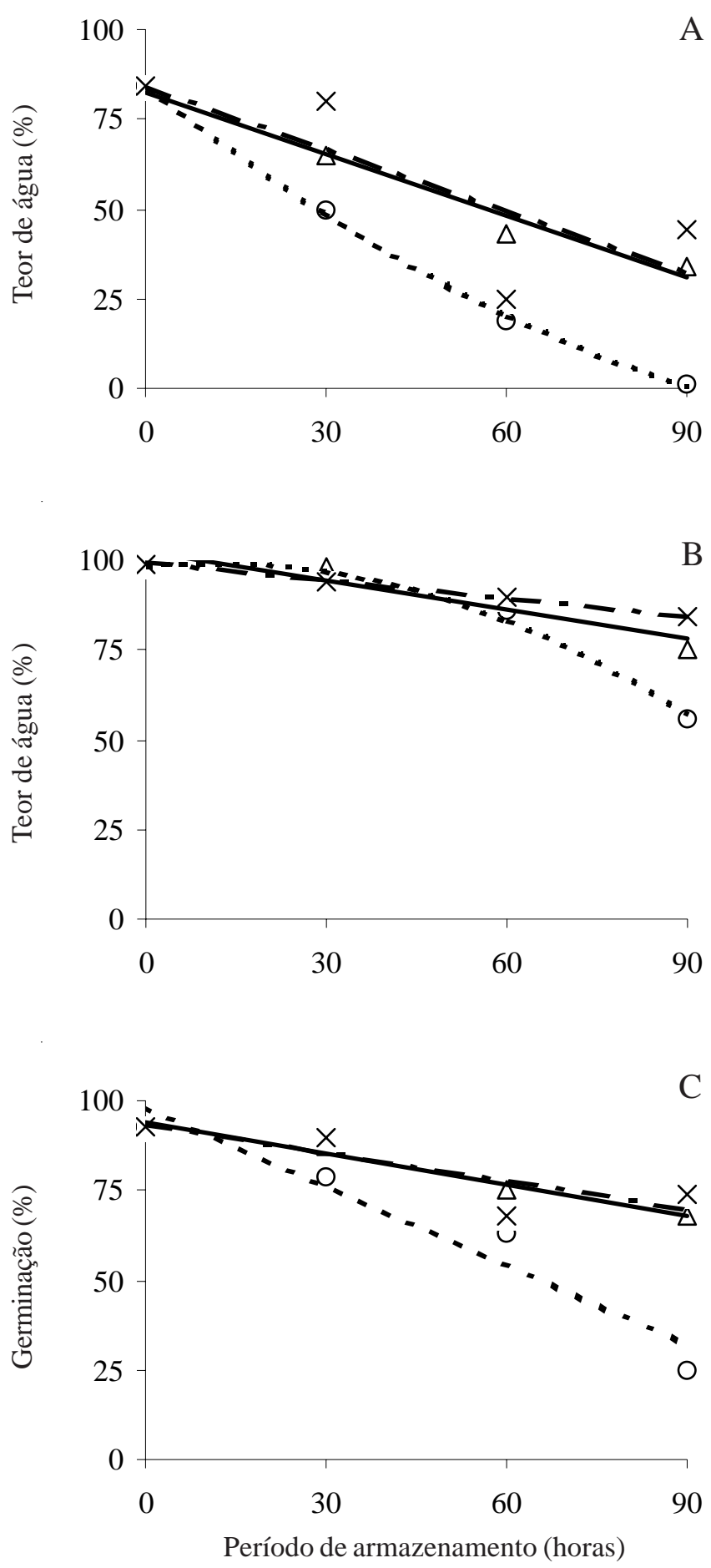

Figura 5. Germinação de embriões de ingá colhidos nos estádios de maturação fruto verde (A), fruto verde-claro (B) e fruto amarelo (C), submetidos ao armazenamento nos potenciais osmóticos de 0,0 MPa (O, ---), -1,6 MPa $(\Delta,-)$ e -2,4 MPa $(\mathrm{X},---)$. Regressões $(P<0,05): \mathrm{Y}_{0 \mathrm{MPa}, \mathrm{A}}=84,5-1,33 \mathrm{X}+0,0044 \mathrm{X}^{2}$ $\left(\mathrm{R}^{2}=0,99\right) ; \mathrm{Y}_{-1,6 \mathrm{MPa}, \mathrm{A}}=82,3-0,5733 \mathrm{X}\left(\mathrm{R}^{2}=0,97\right) ; \mathrm{Y}_{-2,4 \mathrm{MPa}, \mathrm{A}}=84,5$ - 0,5833X $\left(\mathrm{R}^{2}=0,62\right) ; \mathrm{Y}_{0 \mathrm{MPa}, \mathrm{B}}=98,05+0,1683 \mathrm{X}-0,0069 \mathrm{X}^{2}$ $\left(\mathrm{r}^{2}=0,98\right) ; \mathrm{Y}_{-1,6 \mathrm{MPa}, \mathrm{B}}=102,4-0,27 \mathrm{X}\left(\mathrm{r}^{2}=0,88\right) ; \mathrm{Y}_{-2,4 \mathrm{MPa}, \mathrm{B}}=99,1-$ $0,1633 X\left(R^{2}=0,99\right) ; Y_{0 M P a, C}=98-0,733 X\left(R^{2}=0,93\right) ; Y_{-1,6 \mathrm{MPa}, \mathrm{C}}=$ $93,8-0,29 X\left(R^{2}=0,98\right) ; Y_{-2,4 M P a, C}=93,1-0,2633 X\left(R^{2}=0,70\right)$.

\section{Referências bibliográficas}

BARBEDO, C.J. \& CICERO, S.M. 1998. Utilização do teste de condutividade elétrica para previsão do potencial germinativo de sementes de ingá. Scientia Agricola 55:249-259.

BARBEDO, C.J. \& CICERO, S.M. 2000. Effects of initial quality, low temperature and ABA on the storage of seeds of Inga uruguensis, a tropical species with recalcitrant seeds. Seed Science and Technology 28:793-808.

BARBEDO, C.J. \& MARCOS FILHO, J. 1998. Tolerância à dessecação em sementes. Acta Botanica Brasilica 12:145-164.

BILIA, D.A.C. \& BARBEDO, C.J. 1997. Estudos da germinação e armazenamento de sementes de Inga uruguensis Hook. et Arn. Científica 25:379-391.

BILIA, D.A.C., MARCOS FILHO, J. \& NOVEMBRE, A.D.C.L. 1999. Desiccation tolerance and seed storability of Inga uruguensis Hook. et Arn. Seed Science and Technology 27:77-89.

BILIA, D.A.C., BARBEDO, C.J., CICERO, S.M. \& MARCOS FILHO, J. 2003. Ingá: uma espécie importante para recomposição vegetal em florestas ripárias, com sementes interessantes para a ciência. Informativo ABRATES 13:26-30.

BRASIL. Ministério da Agricultura e Reforma Agrária. 1992. Regras para análise de sementes. SNAD/DNDU/CLAV, Brasília.

CARVALHO, L.F., MEDEIROS-FILHO, S., ROSSETTI, A.G. \& TEÓFILO, E.M. 2000. Condicionamento osmótico em sementes de sorgo. Revista Brasileira de Sementes 22:185-192.

CASTRO, R.D., BRADFORD, K.J. \& HILHORST, H.W.M. 2004a. Desenvolvimento de sementes e conteúdo de água. In Germinação: do básico ao aplicado (A.G. Ferreira \& F. Borghetti, orgs.). Artmed, Porto Alegre. p.51-67.

CASTRO, R.D., BRADFORD, K.J. \& HILHORST, H.W.M. 2004b. Embebição e reativação do metabolismo. In Germinação: do básico ao aplicado (A.G. Ferreira \& F. Borghetti, orgs.). Artmed, Porto Alegre. p.149-162.

FARIA, J.M.R., VAN LAMMEREN, A.A.M. \& HILHORST, H.W.M. 2004. Desiccation sensitivity and cell cycle aspects in seeds of Inga vera subsp. affinis. Seed Science Research 14:165-178.

Figure 5. Germination of ingá embryos from green (A), lightgreen (B) and yellow (C) fruits, stored at 0.0 MPa (O, ---), -1.6 $\operatorname{MPa}(\Delta,-)$ and $-2.4 \mathrm{MPa}(\mathrm{X},---)$. Regressions $(P<0.05)$ : $\mathrm{Y}_{0 \mathrm{MPa}, \mathrm{A}}=84.5-1.33 \mathrm{X}+0.0044 \mathrm{X}^{2}\left(\mathrm{R}^{2}=0.99\right) ; \mathrm{Y}_{-1.6 \mathrm{MPa}, \mathrm{A}}=82.3-$ $0.5733 X\left(R^{2}=0.97\right) ; Y_{-2.4 M P a, A}=84.5-0.5833 X\left(r^{2}=0.62\right)$; $\mathrm{Y}_{0 \mathrm{MPa}, \mathrm{B}}=98.05+0.1683 \mathrm{X}-0.0069 \mathrm{X}^{2}\left(\mathrm{r}^{2}=0.98\right) ; \mathrm{Y}_{-1.6 \mathrm{MPa}, \mathrm{B}}=102.4$ - 0.27X ( $\left.\mathrm{r}^{2}=0.88\right) ; \mathrm{Y}_{-2.4 \mathrm{MPa}, \mathrm{B}}=99.1-0.1633 \mathrm{X}\left(\mathrm{R}^{2}=0.99\right)$; $\mathrm{Y}_{0 \mathrm{MPa}, \mathrm{C}}=98-0.733 \mathrm{X}\left(\mathrm{R}^{2}=0.93\right) ; \mathrm{Y}_{-1.6 \mathrm{MPa}, \mathrm{C}}=93.8-0.29 \mathrm{X}$ $\left(\mathrm{R}^{2}=0.98\right) ; \mathrm{Y}_{-2.4 \mathrm{MPa}, \mathrm{C}}=93.1-0.2633 \mathrm{X}\left(\mathrm{R}^{2}=0.70\right)$. 
FERREIRA, A.G. \& BORGHETTI, F. 2004. Germinação: do básico ao aplicado. Artmed, Porto Alegre.

FIGLIOLIA, M.B. \& KAGEYAMA, P.Y. 1994. Maturação de sementes de Inga uruguensis Hook et Arn. em floresta ripária do rio Moji-Guaçu, Município de Moji-Guaçu. Revista do Instituto Florestal 6:15-52.

GOLDBACH, H. 1979. Imbibed storage of Melicoccus bijugatus and Eugenia brasiliensis (E. dombeyi) using abscisic acid as a germination inhibitor. Seed Science and Technology 7:403-406.

HOEKSTRA, F.A., GOLOVINA, E.A. \& BUITINK, J. 2001. Mechanisms of plant desiccation tolerance. Trends in Plant Science 6:431-437.

JOLY, A. B. 1993. Botânica: introdução à taxonomia vegetal. $11^{\text {a }}$ ed. Nacional, São Paulo.

MICHEL, B.E. \& KAUFMANN, M.R. 1973. The osmotic potencial of polyethyline glycol 6000. Plant Physiology 51:914-916.

MUNSELL COLLOR COMPANY. 1952. Munsell color charts for plant tissues. Munsell Collor Company, Baltimore.

OLIVEIRA, D.M.T. \& BELTRATI, C.M. 1992. Morfologia e desenvolvimento das plântulas de Inga fagifolia e I. uruguensis. Turrialba 42:306-313.

PAMMENTER, N.W., BERJAK, P., FARRANT, J.M., SMITH, M.T. \& ROSS, G. 1994. Why do stored hydrated recalcitrant seeds die? Seed Science Research 4:187-191.
PAMMENTER, N.W., BERJAK, P., WESLEY-SMITH, J. \& WILLIGEN, C.V. 2002. Experimental aspects of drying and recovery. In Desiccation and survival in plants: drying without dying (M. Black \& H.W. Pritchard, eds.). CABI Publishing, New York. p.93-110.

PENNINGTON, T. D. 2000. The genus Inga. Royal Botanic Gardens, Kew.

PERTEL, J., DIAS, D.C.F., DIAS, L.A.S. \& ALVARENGA, E.M. 2001. Efeito do condicionamento fisiológico na germinação e no vigor de sementes de café (Coffea arabica L.). Revista Brasileira de Armazenamento 3 (especial):39-45.

POWELL, A.A. 1998. Seed improvement by selection and invigoration. Scientia Agricola 55(especial):126-133.

ROBERTS, E.H. 1973. Predicting the storage life of seeds. Seed Science and Technology 1:499-514.

STEUTER, A.A., MOZAFAR, A. \& GOODIN, J.R. 1981. Water potencial of aqueous plolyethylene glycol. Plant Physiology 67:64-67.

SUN, W.Q. 2002. Methods for the study of water relations under desiccation stress. In Desiccation and survival in plants: drying without dying (M. Black \& H.W. Pritchard, eds.). CABI Publishing, New York. p.47-91.

VIEIRA, S. \& HOFFMANN, R. 1989. Estatística experimental. Atlas, São Paulo. 